\title{
The missing step to building a lunar spaceport
}

\author{
Marc Labriet ${ }^{1}$ \\ International Space University, Illkirch, France, 67400 \\ Lucie Poulet $^{2}$ \\ Deutsches Zentrum für Luft und Raumfahrt (DLR), Bremen, Germany, 28359
}

\begin{abstract}
There is a broad agreement that the cost of launching sufficient mass for long-duration missions towards deep space destinations is prohibitive. One of the most obvious solutions is to use in-space fuel depots containing in situ derived propellants. With 600 million tons of water ice estimated at its north pole and a resource rich regolith, the moon is the most promising and accessible location for in situ production of propellants. However building a lunar base with a regolith processing plant would cost billions of dollars and would face strong political challenges.
\end{abstract}

The Operations and Service Infrastructure for Space (OASIS) team, proposes an innovative solution to the initial financial risks by developing a spaceport network architecture step by step and investing the commercial profits of each iteration into the next node. The initial nodes of the network consist of spaceports in Low Earth Orbit (LEO) and on the Moon.

The most profitable market of the space industry is the commercial communication satellite market. The first spaceport node is to be established in LEO, addressing the mature LEO - GEO (Geostationary orbit) market with 'tugging' services for commercial satellites and in-orbit refueling for exploration missions. The 'tug' service would allow customers to place heavier spacecrafts in GEO for cheaper by always sending the maximum mass and use smaller launch vehicles to enter the GEO market. This service is the initial source of business in order to make the overall network economically viable in the long run.

This second spaceport node on the Moon will produce inexpensive propellant from in situ resources and will make it accessible in LEO revolutionizing space transportation costs and ensuring a strong business case for the network.

The solution incorporates a discussion of the complete Node 1 architecture with an emphasis placed on the business case, as well as the concepts of operations of the spaceport and tug servicer.

$\begin{array}{ll}\text { ECA } & =\text { Evolution Cryotechnique type A } \\ \text { ESA } & =\text { European Space Agency } \\ \text { GEO } & =\text { Geostationary Equatorial Orbit } \\ \text { GTO } & =\text { Geostationary Transfer Orbit } \\ \text { ISS } & =\text { International Space Station } \\ \text { ISU } & =\text { International Space University } \\ \text { ISRU } & =\text { In-Situ Resource Utilization } \\ \text { kg } & =\text { Kilogram } \\ \text { KSC } & =\text { Kennedy Space Center } \\ \text { LCROSS } & \text { Lunar CRater Observation and Sensing Satellite } \\ \text { LEO } & =\text { Low Earth Orbit } \\ \text { LH }_{2} & =\text { Liquid Hydrogen } \\ \text { LO } & =\text { Liquid Oxygen } \\ \text { NASA } & =\text { National Aeronautics \& Space Administration }\end{array}$

${ }^{1}$ Project Manager, Advanced Services, 150 W Tasman Dr, San Jose, CA 95134

${ }^{2}$ Research Associate, System Analysis Space Segment, Robert-Hooke Str. 728359 Bremen, Germany

1

American Institute of Aeronautics and Astronautics 


$\begin{array}{ll}\text { OASIS } & =\text { Operations And Service Infrastructure for Space } \\ \text { PILOT } & =\text { Precursor ISRU Lunar Oxygen Testbed } \\ \text { SSP } & =\text { Space Studies Program } \\ \mathrm{t} & =\text { Metric Tonne } \\ U S & =\text { United States of America } \\ \Delta \mathrm{V} & =\text { Delta Velocity }(\mathrm{km} / \mathrm{s} / \mathrm{kg})\end{array}$

\section{Introduction}

$\mathrm{H}$ ISTORY has proven on numerous occasions that open networks developed step by step offer tremendous results. They often start as limited and expensive governmental projects financed and built for a specific goal. Only when they become open to commercial activities, do they grow beyond expectations. The Roman roads and the spice trade are case studies of such networks which enabled the cultural and economic development of civilizations across the world. They required reliable and safe routes through great distances connecting people who traded local resources. Powerful cities emerged, interconnecting those profitable routes and allowing the cost of transportation of goods, people and ideas to adapt to the growing market.

The same concept can be applied to outer space. Since the middle of the 20th century, access to space has been limited to a few national space agencies. During the last decade, the birth of space tourism and the founding of private space companies show the beginning of a new era where regular access to Low-Earth Orbit (LEO) and beyond opens new opportunities across all industries. However, the necessary infrastructures to support new space activities is still lacking and the cost of launching mass into orbit is prohibitive. The main limitation to space exploitation is that all consumables for any mission is carried from Earth making propellant up to $90 \%$ of the spacecraft mass and volume, preventing heavy payloads to be carried into orbit.

As part of the International Space University (ISU) Space Studies Program 2012, the international team OASIS (Operations And Service Infrastructure for Space) proposed a solution to this problem: an in-space multi-purpose logistics network to provide overall support for exploration and commercial operations. Just like a gas station near a freeway allows drivers to go further, a spaceport on the surface of the Moon would offer the infrastructure, the resources, and the services to grow space activities in the vicinity of the Earth while enabling larger spacecrafts to travel to deep space destinations faster than before.

Recent technological developments and large resource discovery make the Moon the next logical hub to travel into the solar system. These advances include ${ }^{2}$ :

a) Robotics (e.g. Robonaut)

b) Advanced additive and digital manufacturing (3D printing of metallic and polymer parts)

c) Confirmation of lunar volatiles resources as well as carbon and metals in the regolith ( NASA LCROSS/LRO)

d) In-situ resource utilization processes and prototypes (NASA technology development, ROxygen, PILOT) ${ }^{5}$

One key point of this concept is the generation of inexpensive propellant by In-Situ Resource Utilization (ISRU) from the surface of the Moon. To reduce the total initial mass required, the lunar base would be unammed at first. All operations would be teleoperated from Earth. By launching a minimum of 12 to 41 metric tons of "seed" hardware to the Moon, the boot strapping process can begin ${ }^{5}$.

However a kilogram transported from Earth to the Moon is estimated at US $\$ 80,000$ ranging the total transportation cost from US $\$ 960$ Million to US $\$ 3.28$ Billion.. Adding, the cost of design, development, test and operations over several years raises the price tag to tens of billions of U.S. dollars. Given the uncertainty regarding public space investments, we conclude that there is a missing step preventing us from affording the construction of a lunar spaceport. 


\section{The OASIS Solution}

The OASIS concept describes a network of spaceports extending the current terrestrial architecture (Node 0 Kennedy Space Center) into space through several nodes. To lower the risk of the first investment, OASIS proposes to develop the network of spaceports node by node, investing the commercial profits of each one to finance the next through successfive phases (short term, medium term and long term).

The operational viability of the spaceport network is highly dependent on whether or not the network is making a profit and therefore can build on its profits to upgrade its infrastructure and expand to other locations in Space. To raise enough capital to build spaceport Node 2 on the surface of the Moon, sufficient revenue from services offered at Node 1 must be generated to cover the operational cost and recover the initial investment after some years. The most profitable market is the mature communications satellite market in Geostationary Earth orbit (GEO).

Low Earth Orbit (LEO), High Elliptical Orbit (HEO), and Earth Moon Lagrangian Points (EML-1/2) were evaluated with the following criteria:

- Accessibility: a location that could provide an easily accessible point, able to support any kind of missions from the Earth to the Moon and beyond

- Potential for profitability: the choice is based on short-term services addressing mature markets to reduce the financial risk for the private and public investors

- Environment: gravity, radiation, space debris, temperature gradients, power generation, resources availability

- Costs:design, construction, development, operational and maintenance

- Maturity of technology required

- Contribution or value for the overall network.

By analyzing travel time, velocity change required, risks and customer needs, the first spaceport node was chosen to be established in LEO during a first phase of the network development (2015-2025). The second spaceport node will be placed on the surface of the Moon in the next phase (2025-2045) (Fig. 1)

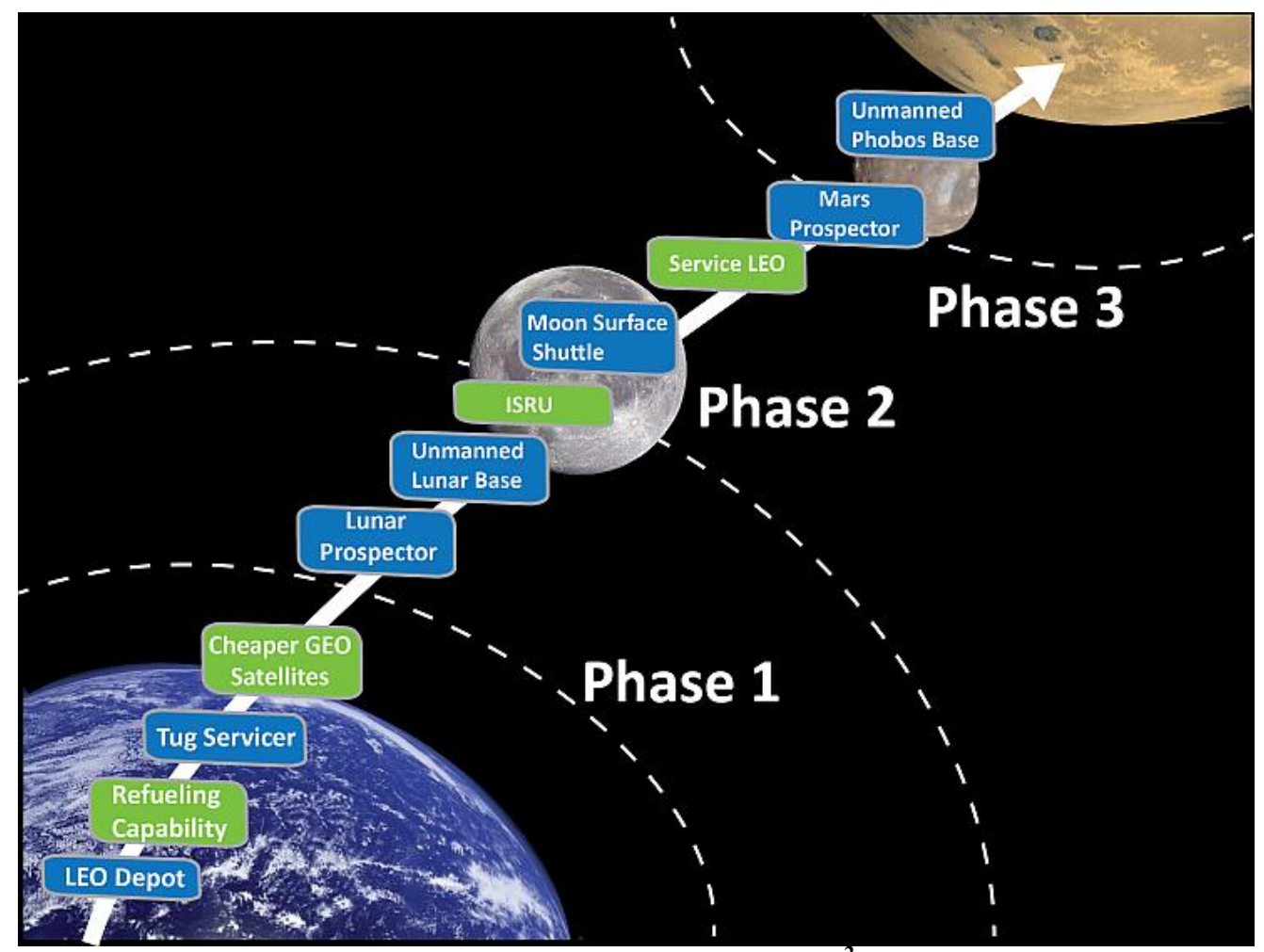

Figure 1: OASIS Phasing Plan ${ }^{2}$

3

American Institute of Aeronautics and Astronautics 


\section{A. Current Launching Capabilities and Price}

For many decades, the high cost of launch services has been one of the biggest obstacles to the growth of space commercialization and exploration. Table 1 summarizes the launching capabilities into GEO, Geostationary Transfer Orbit (GTO) and LEO and associated prices of 10 different current launchers.

Table 1. Launch Vehicle Capability and Price $(2013)^{2}$

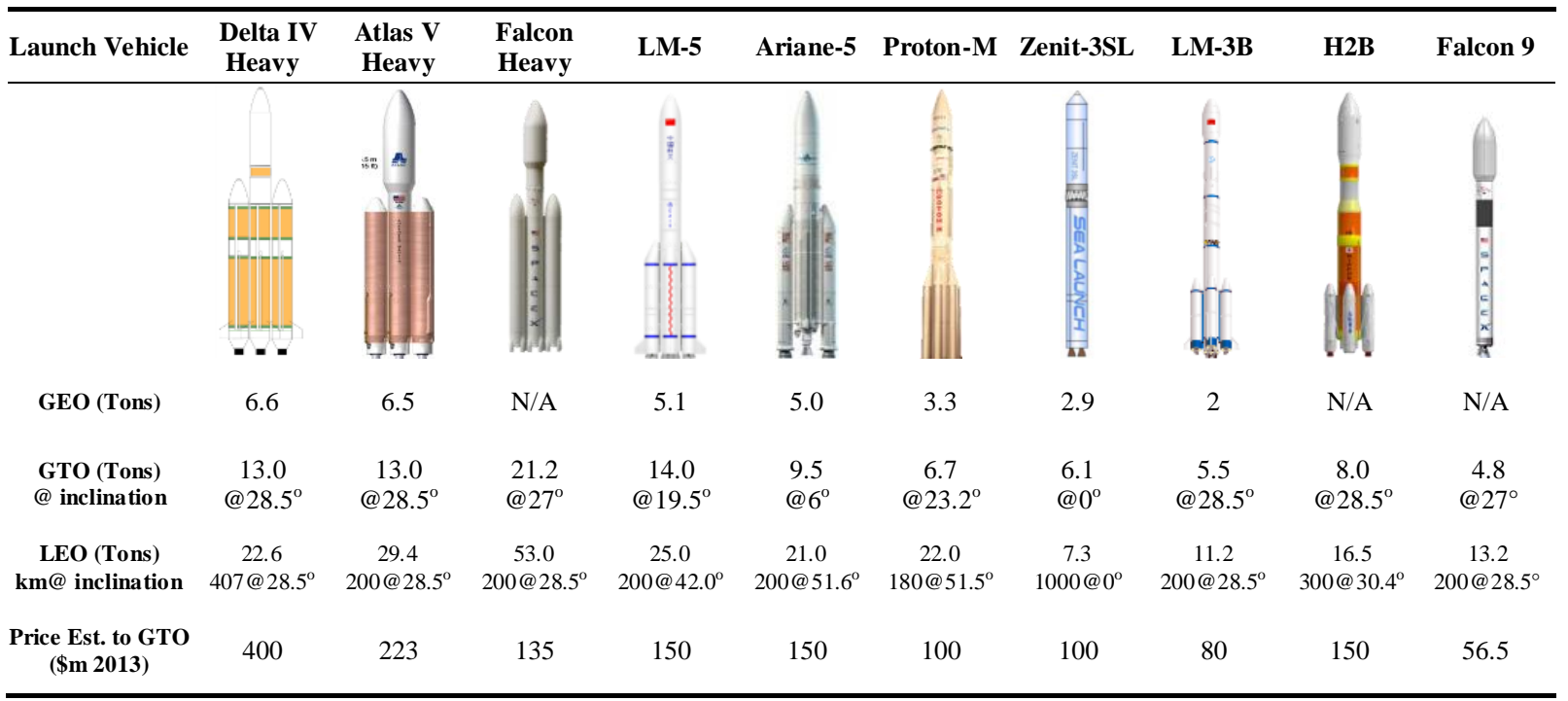

The geostationary spacecraft represent a mature market that has remained stable over the past 10 years consisting of an average of about 20 spacecraft launched per year with an average mass per satellite of 4.0 tons ${ }^{2}$ per spacecraft. Currently about 400 spacecraft are located in GEO providing mainly telecommunications services but sometimes meteorology, navigation, remote sensing and military-related services.

The risk of telecommunication interference limits the number of operational GEO spacecraft. It is expected that the number of spacecraft launched into the GEO orbit will remain between 20-23 satellites per year. However, the average mass per spacecraft is expected to increase as "the trend is to build heavier, more capable satellites", based on the research conducted by Federal Aviation Administration ${ }^{1}$. In the future, the average mass per GEO spacecraft will reach about 4.5 tons per satellite ${ }^{1}$. 


\section{B. Short-Term Services (2012-2025)}

OASIS intends to capture part of this market by providing two mains services; A tug service able to carry a GEO satellite from LEO to GEO and an on-orbit fueling service in LEO. Additional services can be delivered thanks to the flexible design of Spaceport Node 1 (Table 2).

Table 2. List of Potential Services for the short term $(\mathbf{2 0 1 2 - 2 0 2 5})^{2}$

\begin{tabular}{|c|c|c|}
\hline Potential Services & Description & Potential Customers \\
\hline $\begin{array}{l}\text { Tug from LEO to } \\
\text { GEO }\end{array}$ & $\begin{array}{l}\text { Use a tug unit to transport a GEO satellite from } \\
\text { LEO to GEO. Produce propellants at Spaceport } \\
\text { Node } 1 \text { by electrolyzing water provided from } \\
\text { Earth. Load propellant in tug, rendezvous and } \\
\text { connect with the spacecraft and transport to GEO. }\end{array}$ & $\begin{array}{l}\text { Commercial GEO } \\
\text { satellite operators (for } \\
\text { example, Intelsat) }\end{array}$ \\
\hline $\begin{array}{c}\text { On-orbit fueling in } \\
\text { LEO }\end{array}$ & $\begin{array}{l}\text { Use the water depot and electrolyzer in LEO to } \\
\text { provide cryogenic } \mathrm{LO}_{2} / \mathrm{LH}_{2} \text { fueling services to } \\
\text { spacecraft or satellites going beyond LEO. }\end{array}$ & $\begin{array}{l}\text { Space agencies and } \\
\text { commercial planetary } \\
\text { missions }\end{array}$ \\
\hline $\begin{array}{l}\text { Space debris } \\
\text { mitigation } \\
\text { (optional) }\end{array}$ & $\begin{array}{l}\text { Use the tug and the propellant available at the } \\
\text { depot to provide deorbiting services of space } \\
\text { debris from LEO to Earth's atmosphere. }\end{array}$ & $\begin{array}{l}\text { Space agencies and } \\
\text { governments }\end{array}$ \\
\hline $\begin{array}{l}\text { Space structure } \\
\text { decommission } \\
\text { (optional) }\end{array}$ & $\begin{array}{c}\text { Use the tug and a new propellant depot to safely } \\
\text { decommission a large on-orbit structure at the "end } \\
\text { of life". }\end{array}$ & $\begin{array}{l}\text { ISS, Bigelow Aerospace, } \\
\text { Orbital Technology, } \\
\text { Tiangong }\end{array}$ \\
\hline $\begin{array}{l}\text { On-orbit servicing } \\
\text { (optional) }\end{array}$ & $\begin{array}{l}\text { Use a specific spacecraft to provide inspection, } \\
\text { relocation, restoration, repair, augmentation and } \\
\text { assembly services for existing GEO and LEO } \\
\text { satellites. }\end{array}$ & Satellite operators \\
\hline $\begin{array}{l}\text { Warm back-up } \\
\text { (optional) }\end{array}$ & $\begin{array}{l}\text { Provide back-up satellites for GEO satellites } \\
\text { operator in case of emergency/failure of one of the } \\
\text { satellites and depending on the criticality of the } \\
\text { service provided. }\end{array}$ & $\begin{array}{l}\text { Space agencies, } \\
\text { insurance companies, } \\
\text { and commercial } \\
\text { satellites }\end{array}$ \\
\hline
\end{tabular}

\section{Tug Services}

A tug, whose detailed design is in section IV, that transports spacecraft from LEO to GEO, represents the core service provided in the short-term. This service is in direct competition with the upper stages from the launch vehicles servicing the GEO market ${ }^{1}$.

The value proposition of this service for spacecraft operators is the ability to place GEO spacecraft in orbit less expensively. For launch vehicle providers, this service will allow current launch vehicles to place larger, more massive spacecraft in orbit to enhance their revenue. The LEO launch mass limit and maximum amount of propellant that the tug can carry will set the new mass limit for GEO spacecraft.

An additional benefit of providing such a service is the possibility for smaller size launch vehicles (for example, Soyuz) to enter the GEO market by providing the LEO launch segment. A partnership between the spaceport network and smaller launch vehicle providers may reduce the cost of getting to LEO for the spaceport network in exchange for an increased GEO market for the smaller launch vehicle providers.

Spaceport Node 1 in LEO will consist of a water depot, an electrolyzer and a tug, all launched from the surface of Earth. Water launched from Earth will be converted to liquid oxygen $\left(\mathrm{LO}_{2}\right)$ and liquid hydrogen $\left(\mathrm{LH}_{2}\right)$ at the water depot to refuel the tug. When the GEO satellite reaches LEO, the tug separates from the depot and docks to the satellite using the same interface as that used with the launch vehicle. The tug transports the satellite from LEO to either Geostationary Orbit or Geostationary Transfer Orbit (GEO/GTO) using its propellant. Once in GEO/GTO, the tug separates from the satellite and returns to LEO orbit. 
Existing GEO spacecraft launchers charge the full price of the launcher to the GEO spacecraft operator regardless of the actual mass launched. Considering a Falcon 9 launcher from Earth to GTO, the price of the launch services is $\$ 56.5 \mathrm{~m}$ for a maximum mass to GTO of $4.85 \mathrm{t}$ (as of August 2013). If the GEO satellite is $4.85 \mathrm{t}$, the price is the lowest at $\$ 11,649$ per kilogram. On the other hand, if the GEO spacecraft is only $4 \mathrm{t}$, the price per kilogram becomes $\$ 14,125$, an increase of $21 \%$. To offer a competitive price per kilogram for its customers, Ariane maximizes the mass used per launch by offering a dual launch to GTO with a maximum mass of 9.5t. Unfortunately, the number of GEO spacecraft launched per year is limited to 20 satellites. As a result, finding two GEO spacecraft with similar mass, fitting within the Ariane fairing, remains a challenge for Arianespace?

The "tug" service provides another possible solution. The "tug" service enables launches of single or dual GEO spacecraft into LEO and allows the remaining volume/mass in the launcher to be filled with either another LEO spacecraft or water to refill the depot at Spaceport Node 1. This ensures GEO satellite operators a minimum launch cost per kilogram from Earth to LEO for any selected launcher.

As an example of how this process might work, a tug can be designed to transport a $9 t$ payload from LEO to GEO. Currently, the maximum spacecraft mass to GEO is about 6.5t (Table 1). The tug service presents the additional advantage of being able to send more massive spacecraft to GEO. OASIS would still provide the lowest price solution for GTO even after considering a 20\% profit margin for the spaceport. It is to be noted that Falcon Heavy is not considered here, since it is not operational yet but it may impact the profitability of the tug service.

Considering a dual satellite launch from Earth to LEO and using a low-cost launcher to launch water to refill the LEO depot, the spaceport can reach a lower cost structure than conventional GEO satellite launchers. Insurance cost is reduced: instead of insuring two launches, the satellite operators can insure one launch; the launch with the water does not require insurance (nor any additional safety, analysis or testing charges). The water could be sent as a second payload in LEO launches at a reduced price to reach the maximum mass of the launcher. It is to be noted that the tug spacecraft is designed for $9 t$ to GEO, which results in more than $9 t$ of mass to GEO after the circularization maneuver, but only $9 \mathrm{t}$ to GTO is considered for the sake of comparing with other launch solutions.

The total mass of the dual launch is 9t to GTO, the dry mass of the tug is $2.9 t$ (See description of tug in Section IV). The specific impulse is assumed to be constant and 450s. Based on the Tsiolkovsky rocket equation,

$$
\Delta v=I_{s p} \cdot g \cdot \ln \left(\frac{m_{d r y}+m_{p r}}{m_{d r y}}\right),
$$

when re-arranged:

$$
\frac{m_{p r}}{m_{d r y}}=\mathrm{e}^{\frac{\Delta v}{I_{s p} \cdot g}}-1,
$$

where $m_{p r}$ is the mass of the propellant, $m_{d r y}$ is the dry mass of the spacecraft, $I_{s p}$ is the specific impulse, $g$ is the gravitational acceleration of Earth and $\Delta v$ is the required change in velocity for an orbital maneuver.

Considering a $\Delta \mathrm{v}$ of $2400 \mathrm{~m} / \mathrm{s}$ from LEO to GTO and $200 \mathrm{~m} / \mathrm{s}$ from GTO to LEO using aerobrake, the required amount of propellant to transport the tug and both satellites from LEO to GTO and the tug back to LEO is $8,730 \mathrm{~kg}$.

Considering that $1.28 \mathrm{~kg}$ of water produces $1 \mathrm{~kg}$ of propellant, the total amount of water needed is $11,174 \mathrm{~kg}$. Considering a launch cost from Earth to LEO of $\$ 4,300 / \mathrm{kg}$ (Proton: $\$ 4,348 / \mathrm{kg}$; Falcon 9: $\$ 4,296 / \mathrm{kg}$ ) for both satellites. We also consider $\$ 3,450 / \mathrm{kg}$ for the water (based on a $20 \%$ discount due to the reduced integration, launch campaign, purchase and transportation costs of the water on Earth), the total cost to bring both satellites from Earth to GTO is $\$ 77.25 \mathrm{~m}$ without charges. $(\$ 4,300 / \mathrm{kg} * 9 \mathrm{t}+\$ 3,450 / \mathrm{kg} * 11,174 \mathrm{~kg})$

Considering 10\% charges (tug operations and monitoring), the total cost for the OASIS Earth to GTO service is $\$ 85 \mathrm{~m}$ or $\$ 9,443 / \mathrm{kg}$ for communications satellites. Considering a $20 \%$ profit margin, the price charged for both satellites is $\$ 106.2 \mathrm{~m}$ or $\$ 11,802 / \mathrm{kg}$ which is significantly cheaper than other launchers such as Ariane 5 Evolution Cryotechnique type A (ECA) (Estimated cost is $\$ 15,000 / \mathrm{kg}$ to GTO) 
The initial costs, as can be seen in Table 3, consist of the development, manufacturing and testing of the tug, the electrolyzer, solar panels for the electrolyzer and the launch of these. The LEO tank (capable of hosting $30 t$ of water) is counted as operational cost.

\begin{tabular}{cc} 
Tug Servicer & $\$ 241 \mathrm{M}$ \\
Electrolyzer & $\$ 12 \mathrm{M}$ \\
Solar panels & $\$ 3 \mathrm{M}$ \\
Launch & $\$ 56.5 \mathrm{M}$ \\
\hline Total & $\mathbf{\$ 3 1 2 . 5 M}$
\end{tabular}

Table 3. Breakdown of initial costs ${ }^{2}$

\section{LEO On-Orbit Fueling}

Leveraging the existing 30-ton water tank and the electrolyzer in LEO orbit, the spaceport will be able to offer LEO on-orbit fueling to space agencies or commercial missions. The cost per kilogram of propellant provided at the LEO depot is $\$ 4,858 / \mathrm{kg}$ (launching cost for water of $\$ 3,450 / \mathrm{kg}$, considering 1.28 as the conversion ratio from water to propellant and $10 \%$ for charges) and the price charged is $\$ 5,830 / \mathrm{kg}$ considering a $20 \%$ profit margin. It would offer significant cost reduction per kilogram for missions beyond LEO.

\section{On-Orbit Servicing}

Reliability remains a critical requirement for satellites and interplanetary spacecrafts, consequently much attention is given to high quality component development and redundancy in these systems. Nevertheless the harsh effects of space weather, and lack of access once in space, can lead to various on-board technical problems which can result in loss of the entire spacecraft. On orbit servicing could have played a major role in saving the \$163 million Phobos-Grunt mission in 2011. This has led to the concept of on-orbit servicing as means of mitigating these challenges for manufacturers and operators ${ }^{7}$

On-orbit servicing refers to the various procedures carried out in space to enhance the operations and efficiency of a spacecraft. These procedures can be grouped into five general types which include inspect, relocate, restore, augment and assembly ${ }^{4}$.

These five classes of on-orbit servicing are largely interdependent and complementary in nature. In addition the derived advantages and rewards of on-orbit servicing can be listed as follows: reduce risk of mission failure, reduce mission cost, increase mission performance, improve mission flexibility and enable new missions.

\section{Medium-Term Services (2025-45)}

Building on profits and an improved attitude toward orbiting spaceports made during the short-term period, the spaceport network will expand in the medium-term with a second node, Spaceport Node 2. This node consists of a spaceport on the lunar surface that will enable in situ resources extraction and utilization. Indeed, extracting water from mining operations on the Moon's surface to provide propellant to the existing Spaceport Node 1 will significantly decrease the operating cost at Spaceport Node 1 compared to the short-term solution (water from Earth) thus increasing the profit generated by Spaceport Node 1.

The infrastructure of Spaceport Node 1 will also enable the development of Spaceport Node 2 on the Moon at a lower cost, through on-orbit fueling in LEO or even by using the tug from LEO to Lunar orbit. 


\section{Spaceport Node 1: Low Earth Orbit}

Spaceport Node 1 (Fig. 3), consists of an unmanned modular orbital platform located in LEO. Each module provides supports, such as power generation, station keeping, communication, navigation, propellant generation, and docking adapters. Tanks full of water are sent from Earth and connected to the propellant generators, creating cryogenic $\left(\mathrm{LO}_{2} \mathrm{LH}_{2}\right)$ propellants through the process of electrolysis. To reduce storage needs, these propellants are created only when necessary for a mission and are stored directly into the propellant tanks of the tug servicer spacecraft. Additional modules can be stacked together if there is a need to increase the overall capability. Given the power constraints and the size of the market, Spacecraft Node 1 is expected to support four or five missions per year for the duration of Phase 1 of the network (2015-2025).

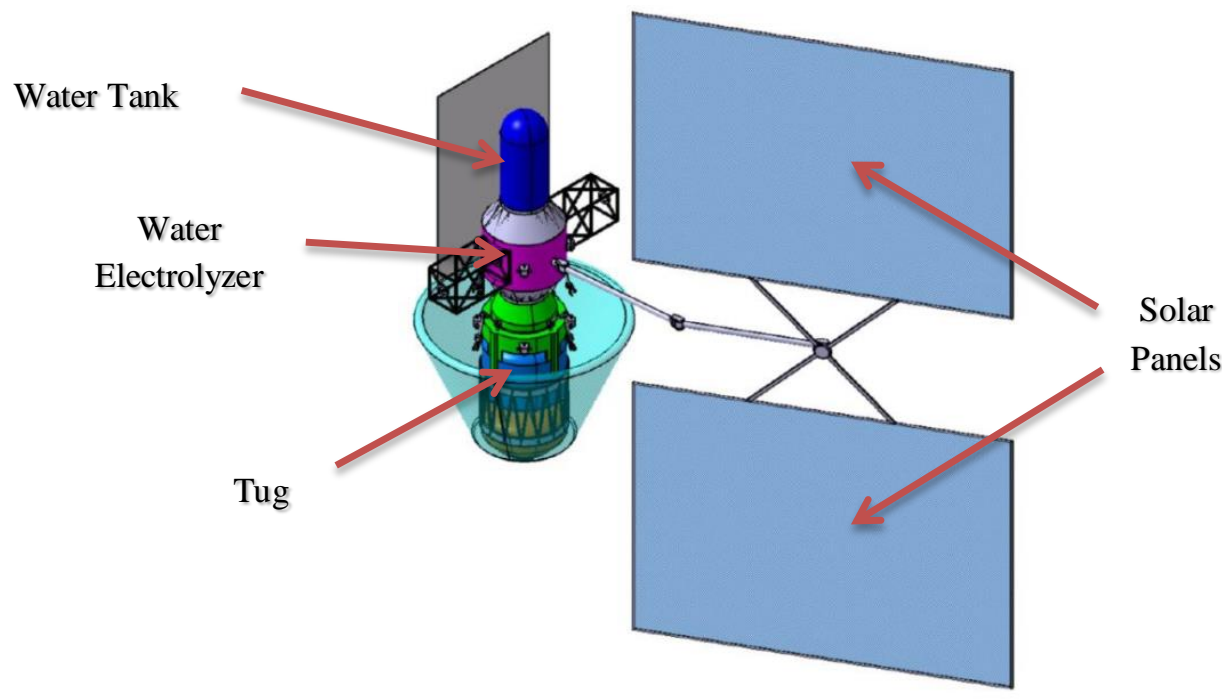

Figure 3: Spaceport Node 1

The tug servicer (Fig. 4)], is a tele-operated spacecraft with robotic arms. It transfers spacecraft from LEO to GTO for orbital inclinations of $0^{\circ}$ to $51.6^{\circ}$ (International Space Station orbit inclination) and circularizes their orbit to GEO, if necessary. The tug carries enough propellant to deliver a nine ton satellite from LEO to GEO and then return to the depot for refueling. The tug is able to save fuel with aero-braking by deploying an inflatable fixed cone on its return from GTO/GEO to LEO.

Table 5. Mass Budget for the Depot ${ }^{2}$

Depot major components

Tank, thermal protection and debris shielding 1500

AOCS

Electrolyzer, radiator and cryocooler

6300

Thin film amorphous silicon photovoltaic arrays $\quad 550$

Communication systems and antennas 


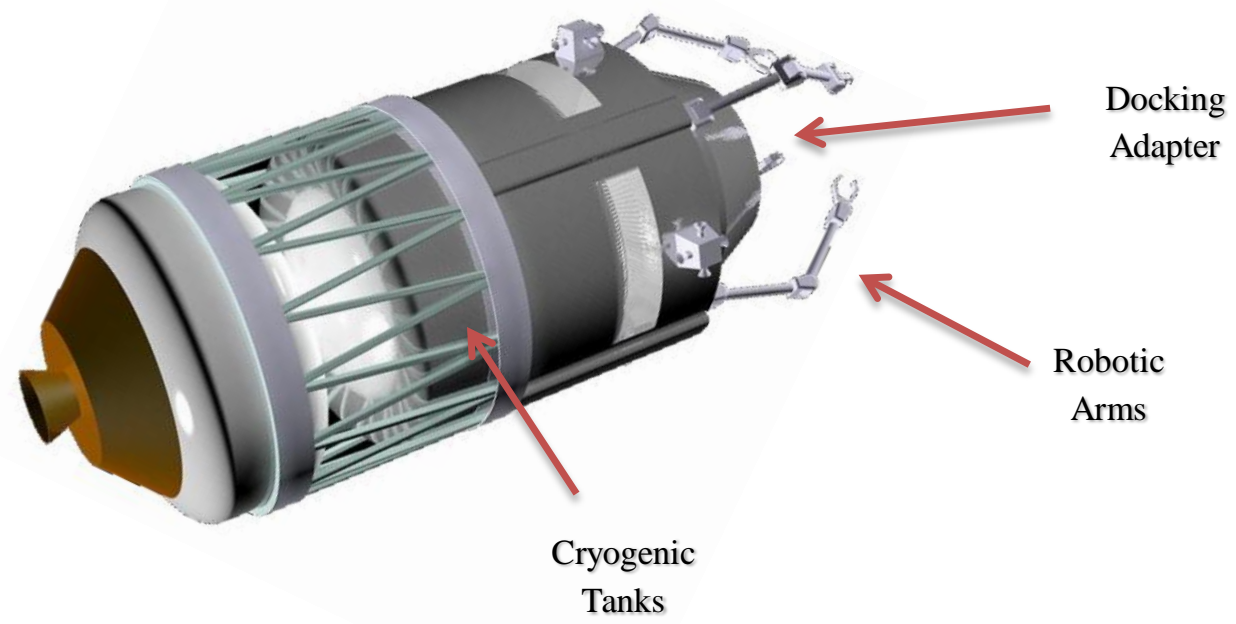

Figure 4: Tug servicer

Based on our assumptions, the dry mass of the tug is 2.9 tons. Calculations shown in Table 6:

Table 6. Mass Budget for the Tug

\begin{tabular}{ll} 
Component & Mass(kg) \\
Robotics & 200 \\
Communication system & 30 \\
Propulsion (includes aero-shell) & 400 \\
AOCS & 50 \\
Structure & 600 \\
Fuel cells & 20 \\
Tanks & 1600 \\
\hline Total for tug & $\mathbf{2 9 0 0}$
\end{tabular}

\section{Concept of operations}

The concept of operations is as follows:

1- Launch of water to LEO;

2- Tug docks with the water tank and takes it to Spaceport Node 1

3- Water is transferred to main water tank and small water tank is de-orbited

4- Water is converted to cryogenic propellant and transferred to the tug

5- Satellite is launched from Earth's surface to LEO

6- Tug rendezvous and docks with satellite

7- Tug moves the satellite to GTO

8- Satellite is placed in GTO

9- Tug returns to LEO using aerobraking

10- Tug docks with depot and another mission is ready to start.

American Institute of Aeronautics and Astronautics 
GTO

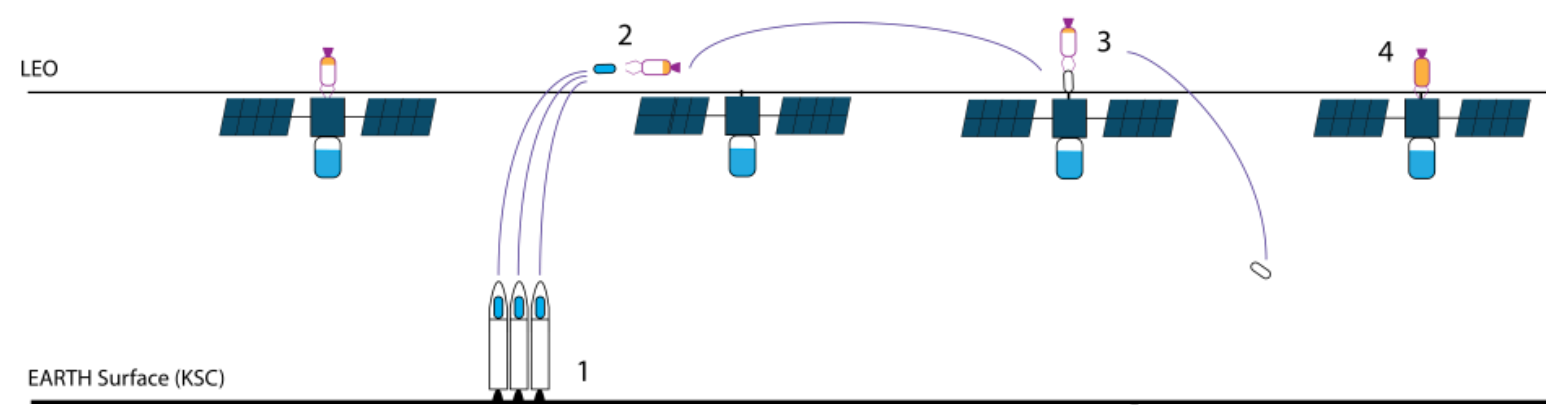

GTO

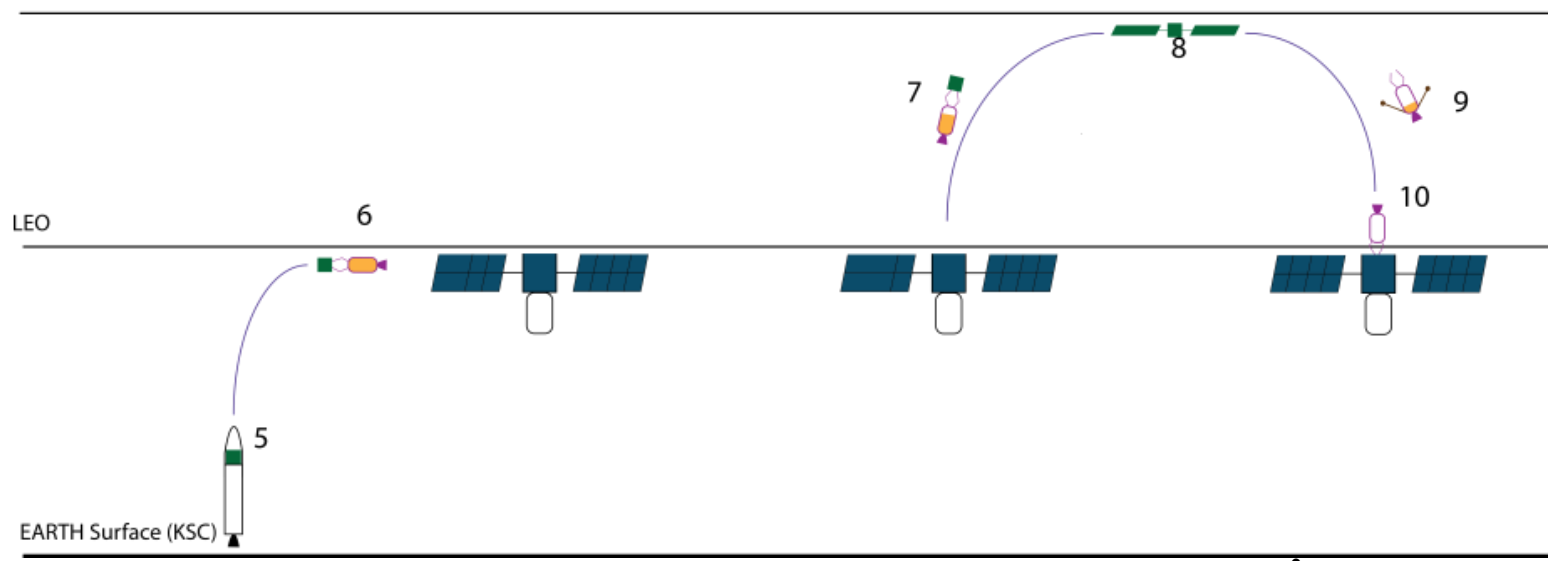

Figure 6: Bat Chart of a Mission with Water Supply from Earth ${ }^{2}$. 


\section{Technologies}

At Spaceport Node 1, the orbital platform provides support like power generation, station keeping, communication, navigation, and docking support to the other elements. An international docking adapter allows different spacecraft to dock. Water tanks connected to the propellant generators (via electrolysis) are directly connected to the tug servicer. It should be noted that the system is modular and more elements can be added to increase the needed capability. Finally, it will provide cryogenic (LO2 and LH2) consumables to service any spacecraft.

The critical technologies to be developed to realize Spaceport Node 1, including test robotic refueling, autonomous rendezvous and docking, and robotic servicing are shown on Figure 7.

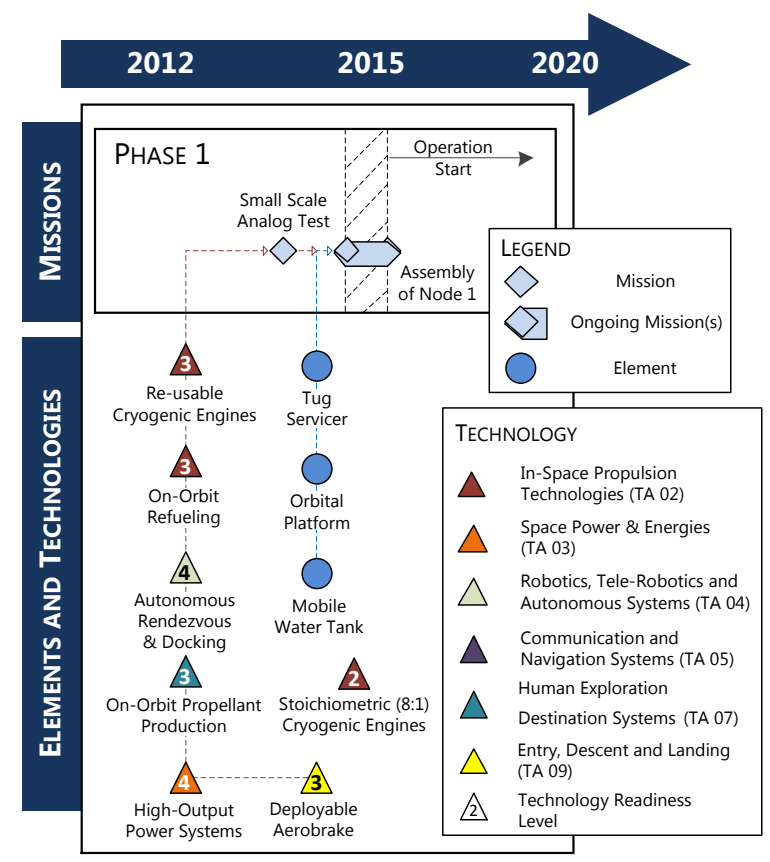

Figure. 7: Roadmap for Phase $1^{2}$

\begin{tabular}{|l|l|c|c|l|}
\hline \multirow{4}{*}{ Phase 1} & \multicolumn{1}{|c|}{ Critical Technology } & $\begin{array}{c}\text { TR } \\
\text { L }\end{array}$ & $\begin{array}{c}\text { T } \\
\text { A }\end{array}$ & \multicolumn{1}{|c|}{ Comment } \\
& $\begin{array}{l}\text { On-orbit propellant production } \\
\left(\mathrm{LH}_{2} \text { and } \mathrm{LO}_{2}\right)\end{array}$ & 4 & 07 & $\begin{array}{l}\text { Propellant production by electrolysis of } \\
\text { water takes place at Spaceport Node 1 }\end{array}$ \\
\cline { 2 - 5 } & On-orbit refueling & $3-4$ & 02 & Necessary for profitable tug operations \\
\cline { 2 - 6 } & Reusable cryogenic rocket engines & $3-4$ & 02 & Necessary for profitable tug operations \\
\cline { 2 - 5 } & High-output power systems & $3-5$ & 03 & Needed for electrolysis \\
\cline { 2 - 5 } & $\begin{array}{l}\text { Deployable aerobrake thermal protection } \\
\text { system }\end{array}$ & $2-4$ & 09 & $\begin{array}{l}\text { Soft aerobraking is performed from GEO } \\
\text { to LEO }\end{array}$ \\
\cline { 2 - 5 } & Autonomous rendezvous and docking & $4-5$ & 04 & Unmanned systems \\
\hline
\end{tabular}

Table 7. Overview of Critical Technologies by Phase 


\section{Conclusion}

The conquest of space will not be achievable without a significant reduction in the effort and cost required to reach it. Only an infrastructure network using in situ resources on the Moon can enable it. Due to the high cost of such an entreprise, and the instable budget of governmental agencies, it is unlikely that a lunar base will ever be completely publicly funded. Team OASIS has created a concept for a network of spaceports extending the existing transportation and logistics infrastructure on Earth into space, node by node by investing the commercial profits of each node into the next one. In the short-term, the first node of the spaceport network is to be established in LEO, addressing the mature LEO - GEO market. As a result, the primary services provided for the first phase (2013-2015) consist of on orbit-refueling and a 'tug' service from LEO to GEO. The 'tug' service is the initial source of business in order to make the overall network economically viable for extending a human presence throughout the Solar System.

\section{Acknowledgments}

This paper is based on the OASIS report (Team OASIS, 2012) which was prepared by an international group of 34 participants from 19 countries during the course of the Space Studies Program 2012 at the International Space University: Melanie Clegg, Vincent Coache, Tyler Dwyer, Shady El Azab, Kristin Freeman, Shai Gerner, Marc Gick, Fei Guan, Yuri Ishizu, Sebastian Klaus, Marc Labriet, Mikkel Ladegaard, Frederico Larangeira, Luliang Lou, Zhuoyan Lu, Qinglang Luo, Nuno Loureiro, Julie Mason, Narasimha Murthy Neeruganti Narasimhulu, Paul Nizenkov, Fredrik Persson, Udrivolf Pica, Lucie Poulet, Maxime Puteaux, Dmitry Rachkin, Eirini Maria Sfantzikaki, Yuan Si, Chrishma Singh-Derewa, Duarte Sousa, Rui Sousa, Suki Dauda Sule, Anna Szwemin, Graeme Taylor, and Aliya Valiyff.

We would like to thank the faculty, staff and alumni of the International Space University for the tremendous support provided at the Florida Institute of Technology, Melbourne, Florida in the Space Studies Program 2012 held during from June - August of 2012. In addition the authors would like to thank NASA, Kennedy Space Center for supporting this effort and the ISU SSP.

\section{References}

\footnotetext{
1 Moranta S, Lionnet P ."Space Trends - Global Space Activity Overview 1986-2011". ASD-EUROSPACE. [online] Available from:http://www.eurospace.o/Data/Sites/1/pdf/spacetrends/eurospacespacetrends2011.pdf [Published May 2012].

${ }^{2}$ Clegg, et. al, ISU Team OASIS “Operations and Service Infrastructure for Space. Team Project: Spaceports”, Final Report Edition, SSP12, Strasbourg, France, International Space University (ISU), 105 pages, 2012.

${ }^{3}$ Larson, W., Gill, T., Mueller, R.P., and Brink, J. "Establishment of a Spaceport Network Architecture”, Paper no. IAC-12D3.2.6, 63 ${ }^{\text {rd }}$ International Astronautics Conference, Naples, Italy, 2012.
}

${ }^{4}$ Long, A., Richards, M., and Hastings, D..’On-Orbit Servicing: A New Value Proposition for Satellite Design and Operation, Journal of Spacecraft and Rockets", 44 (4), pp. 964-976, 2007.

${ }^{5}$ Metzger, P., Muscatello, A., Mueller, R., and Mantovani, J. "Affordable, Rapid Bootstrapping of the Space Industry and Solar System Civilization.” Journal of Aerospace. Engineering. 26, SPECIAL ISSUE: In Situ Resource Utilization, 18-29, 2013.

${ }^{6}$ Mueller, R.P., “Surface Support Systems for Co-Operative and Integrated Human Robotic Lunar Exploration', Paper no. IAC-06-AS.2.09,. 57th International Astronautics Conference, Valencia, Spain, 2006.

${ }^{7}$ Mueller, R.P., Metzger, P.T., and Mantovani, J.G, "Regolith as a resource in solar system human and robotic exploration," paper no. IAC-10-A3.1.7, 61st International Astronautics Conference, Prague, Czech Republic, 2010

${ }^{8}$ Saleh, J.H., Lamassoure, E., Hastings, D.E.. "Space systems flexibility provided by on-orbit servicing: Part 1". Journal of spacecraft and rockets. 39(4), pp.551-560, 2012.

${ }^{9} \mathrm{CNES}$ website: “Europe sets its sights on Ariane 6" http://www.cnes.fr/web/CNES-en/10705-gp-europe-sets-its-sights-onariane-6.php, 2013. 